\title{
SIMULAÇÃO COMPUTACIONAL DA EFICIÊNCIA ENERGÉTICA PARA UMA ARQUITETURA SUSTENTÁVEL
}

\author{
L. K. S. OLIVEIRA*, R. M. RÊGO, M. N. M. A. FRUTUOSO e S. S. F. B. RODRIGUES \\ Instituto Federal de Educação, Ciência e Tecnologia de Pernambuco - IFPE \\ lacyane.krysna@gmail.com.br*
}

Artigo submetido em janeiro/2016 e aceito em julho/2016

DOI: 10.15628/holos.2016.3981

\section{RESUMO}

Este artigo aborda a importância da arquitetura sustentável, discutindo conceitos e definições desta temática, diferenciando a Bioarquitetura, Arquitetura Bioclimática e Arquitetura Sustentável. Explana sobre as vantagens e características de um projeto sustentável, onde destaca a eficiência energética das edificações. Indica métodos de projeto e avaliação da eficiência e qualidade ambiental das edificações como BREEAM, LEED, HQE e Selo Azul, assim como o Programa Brasileiro de Etiquetagem Energética. Explana sobre a aplicação de simulações computacionais para promoção da eficiência energética das edificações exemplificando softwares utilizados atualmente. Explanou-se a semelhança dos diferentes conceitos que relacionam a arquitetura e o uso dos recursos naturais, apesar da existência de termos diferentes. Compararam-se os métodos de avaliação e
\end{abstract}

certificação de projeto, os quais utilizam parâmetros em comum, mas adotam metodologias diversas. Discutiu-se também, a não utilização das ferramentas de simulação computacional da eficiência energética das edificações no cotidiano dos arquitetos. Conclui-se que independente do termo a ser utilizado, o importante é que existe uma reflexão sobre a produção arquitetônica, parâmetros para avaliar o desempenho técnico das edificações, e instrumentos disponíveis para projetar e comprovar a eficiência do uso dos recursos naturais. Necessário se faz explorar a simulação computacional como ferramenta de projeto, bem como de planejamento do uso e operação para buscar a melhoria contínua das edificações e da qualidade do meio ambiente.

PALAVRAS-CHAVE: Sustentabilidade, projeto arquitetônico, energia.

\section{COMPUTER SIMULATION OF ENERGY EFFICIENCY FOR SUSTAINABLE ARCHITECTURE}

\begin{abstract}
This article discusses the importance of sustainable architecture, discussing concepts and definitions of this issue, distinguishing Bioarchitecture, Bioclimatic Architecture and Sustainable Architecture. Explains about the advantages and characteristics of a sustainable project, which highlights the energy efficiency of buildings. Indicates design methods and evaluation of the efficiency and environmental quality of buildings as BREEAM, LEED, HQE and Blue Seal, as well as the Brazilian Program of Energy labeling. Explained the resemblance of the different concepts relating to architecture and the use of natural resources, despite the existence of different terms. Compared the methods of assessment and certification of project, which use parameters in
\end{abstract}

common, but adopt different methodologies. And discussed the non-utilisation of computational simulation tools of the energy efficiency of buildings in the daily lives of the architects. It is concluded that independent of the term being used, the important thing is that there is a reflection on the architectural production, parameters to assess the technical performance of buildings, and instruments available to design and demonstrate the efficiency of the use of natural resources. Required if makes exploring the computer simulation as a tool for design, as well as use and operation planning to seek continuous improvement of buildings and the quality of the environment.

KEYWORDS: Sustainability, architectural design, energy. 


\section{INTRODUÇÃO}

Em 2005, Hickel já dizia que a arquitetura passa por uma crise de identidade. A arquitetura moderna baseava-se "na aceitação da progressividade historicamente inevitável, de habitar em configurações urbanas, entendendo a natureza como fonte inesgotável, capaz de sustentar seus processos técnicos culturais". Mas a partir dos desequilíbrios do desenvolvimento e da globalização, os recursos naturais não são suficientes para atender as demandas de consumo da sociedade, e a arquitetura atual não responde corretamente as demandas do nosso tempo. $\mathrm{O}$ autor alerta que a arquitetura deve ser pensada de acordo com os valores de seu tempo, que os fatores tempo e espaço devem definir o papel da arquitetura. É tempo de discutir e incorporar o conceito de sustentabilidade, como nas demais áreas do conhecimento. Tempo de discutir como a arquitetura se relaciona com a situação de finitude e escassez de recursos, que nos obrigam a utilização cuidadosa.

Roberto Fernandez apud Hickel (2005) comenta que a arquitetura esteve muitas vezes relacionada ao fazer sem conhecer a realidade e ao fazer repetindo-se, imitando-se. Gonçalves e Duarte (2006) complementam esta situação foi comum a partir da Segunda Guerra Mundial, quando o International Style e a "crença de que a tecnologia de sistemas prediais oferecia meios para o controle total das condições ambientais de qualquer edifício, levou à repetição das caixas de vidro e ao inerente exacerbado consumo de energia nas décadas seguintes, espalhando-se por cidades de todo o mundo". Entretanto, é comum verificar a produção de edificações que ignoram as características locais nos dias atuais, por isto é necessário refletir sobre a sua produção arquitetônica, para não correr o risco da atitude imitativa e uso de analogias indevidas que prejudicam a sustentabilidade.

Por si só, o fato de trabalhar a "favor da realidade" é uma atitude sustentável que implica um discernimento por parte da arquitetura para com o meio onde está inserida. Aproximando-se do nosso contexto brasileiro significa levar em conta nossos aspectos sociais, ambientais e econômicos (evitando excessos tecnológicos e a dependência da técnica e inventando uma arquitetura feita de adaptações à realidade). Se a concepção compreende ecologia, deve aceitar a realidade deixar de normatizar e de reproduzir modelos. A ecologia vai além da técnica. O problema ambiental vai junto com a preservação da identidade cultural, do genius loci, das condições climáticas e geográficas (HICKEL, 2005)

Não se pretende com isso, afirmar que a arquitetura sustentável, adequada ao seu tempo e localidade, por si só é capaz de resolver os problemas ambientais do planeta, mas sim reconhecer o potencial da sua contribuição para a criação de habitats humanos sustentáveis (EDWARDS, 2008, p.7).

O objetivo deste artigo é discutir conceitos, características e vantagens da arquitetura sustentável, bem como a importância da eficiência energética das edificações e os métodos e instrumentos para inserir esta preocupação no processo de projeto arquitetônico. Para isso, será realizada uma revisão de literatura que atualize o estado da arte deste tema. 


\section{REVISÃO BIBLIOGRÁFICA}

\subsection{Arquitetura sustentável, bioclimática e bioarquitetura}

A abordagem ecológica integra a arquitetura desde os primórdios, ainda que não fossem utilizados os termos atuais. Segundo Edwards (2008, p.37), Vitrúvio em seus textos, defendia que conforto e clima faziam parte do modelo triangular de firmitas, vetustas e utilitas (solidez, beleza e utilidade), defendia a importância da existência da iluminação e ventilação natural e acreditava que o projeto arquitetônico deveria ser um agente mediador entre o conforto interno e o ambiente externo.

Corbella e Yannas (2003, p.16), corroboram da opinião que desde os primórdios de nossa civilização, os arquitetos se preocuparam com o conforto e em consumir pouca energia para consegui-los. Entretanto, por muito tempo, esses conceitos foram esquecidos e apenas um pequeno grupo de arquitetos insistia em projetar edifícios adaptados ao clima local e que seguiu pesquisando e desenvolvendo o tema.

O esquecimento dos conceitos de conforto por parte dos arquitetos, foi evidente após a Segunda Guerra Mundial, quando se expandiram as técnicas construtivas, havia abundância de combustível e o uso da tecnologia da produção e de novos equipamentos intensificava-se na engenharia. As escolas de arquitetura propagavam que o conforto térmico da edificação era tarefa do engenheiro térmico e a iluminação natural podia ser substituída pela artificial, que era tarefa do engenheiro eletricista, ambas eram profissões emergentes.

Esta época foi de intensa exploração de sistemas artificiais nas edificações através do desenvolvimento da tecnologia, o que demandou grande consumo de energia.

\footnotetext{
O grande aumento do consumo de energia necessário para solucionar os problemas criados por este tipo de arquitetura não era levado em conta porque seu custo era irrisório. E ainda não existia uma consciência generalizada sobre a enorme poluição criada pela geração e o consumo dessa energia. (CORBELLA;YANNAS, 2003, p.16)
}

Entretanto, na década de 1970, com a primeira crise de energia, produzida pelo elevado aumento do preço do petróleo, sentiu-se a necessidade de produzir edificações com a preocupação do consumo energético. Iniciou-se a incorporação de energia solar aos edifícios como alternativa à energia convencional, bem como retornou a consciência de aproveitamento dos recursos naturais para promoção do conforto dos usuários. Corbella e Yannas (2003, p.17) afirmam que "[...]foi renascendo uma arquitetura preocupada na sua integração com o clima local, visando à habitação centrada sobre o conforto ambiental do ser humano e sua repercussão no planeta, a Arquitetura Bioclimática". Já Brian Edwards (2008, p.37) afirma que foi nesta década que "o projeto ecológico tornou-se uma disciplina própria da formação dos arquitetos", ainda que com uma abordagem focada na economia de energia.

A arquitetura Bioclimática citada por Corbella e Yannas (2003, p.37), tem como objetivo "prover um ambiente construído com conforto físico, sadio e agradável, adaptado ao clima local, que minimize o consumo de energia convencional e precise da instalação de menor potência elétrica possível, o que também leva à mínima produção de poluição". Para Adam (2011, p.57): 
A arquitetura bioclimática, investiga as relações entre os seres humanos (animais homotérmicos) e as características climáticas de um local, que são absorvidas e transformadas pelos edifícios, refletindo-se no partido arquitetônico (orientação dos ambientes, lay-outs, disposição das vedações - paredes e cobertura -, proporção e composição das aberturas, estruturas, materiais e paisagismo) com o objetivo de minimizar a quantidade de energia operante consumida no edifício.

Percebemos que ambos os conceitos destacam a relação com o clima local e a redução do consumo energético. A consideração destes dois fatores na concepção arquitetônica influencia tanto a forma e estética das edificações, como a disposição das atividades nos ambientes e a sua relação com o meio externo, sejam de proteção contra as intempéries ou ampliando a relação com a natureza, através de espaços verdes.

A arquitetura Bioclimática avançou em pesquisas científicas a partir de dados climáticos. Hoje temos disponível dados de intensidade, velocidades e direção dos ventos, umidade, radiação solar, diagramas das cartas solares que demonstram a insolação para as diferentes fachadas de uma edificação ao longo do ano, em diferentes localidades. Além de diversos softwares que são instrumentos para o projeto arquitetônico, simulando a realidade para auxiliar a proposição de soluções.

Em paralelo à Arquitetura bioclimática, e possivelmente anterior a esta, se desenvolvia a bioconstrução. Segundo Adam (2011, p.41)

A bioconstrução, também conhecida por ecobioconstrução, nasceu nos países germânicos, (bau-biologie - biologia da construção), e diz respeito ao relacionamento entre edifício e vida, o impacto das construções na saúde humana e a integração ecológica entre a vida humana e outros tipos de vida, visando o bem-estar global.

A bioconstrução se diferencia da Arquitetura Bioclimática por não haver uma forte relação com o clima e com as peculiaridades de cada local. Refere-se às edificações construídas explorando-se materiais naturais e que provocam baixo impacto ao sítio onde são implantadas, além de promover a integração com o ambiente externo. A bioconstrução é frequentemente relacionada a uma arquitetura vernacular, espontânea, tradicional. Segundo Edwards (2008, p.167), "a arquitetura vernacular utiliza materiais disponíveis no local, fontes de energia locais, em sua grande maioria renováveis, e adota métodos construtivos que incentivam a reciclagem e o respeito a natureza" e com ela é possível aprender lições de sustentabilidade para edificações rurais ou urbanas.

Para Corbellas e Yannas (2008, p.17), a Arquitetura Sustentável "é a continuidade mais natural da Bioclimática, considerando também a integração do edifício à totalidade do meio ambiente, de forma a torná-lo parte de um conjunto maior".

É a arquitetura que quer criar prédios objetivando o aumento da qualidade de vida do ser humano no ambiente construído e no seu entorno, integrado com as características da vida e do clima locais, consumindo a menor quantidade de energia compatível com o conforto ambiental, para legar um mundo menos poluído para as futuras gerações. 
O conceito de arquitetura sustentável é amplo e agrega ideias da bioarquitetura e da arquitetura bioclimática. Segundo os arquitetos Fosters e Partners (1999) apud Edwards (2008), um "projeto sustentável é a criação de edificações eficientes do ponto de vista energético, saudáveis, confortáveis, de uso flexível e projetadas para terem uma longa vida útil". Já a Associação para Informação e Pesquisa sobre as Instalações dos Edifícios (Building services Research and Information Association - BRSIA, 1996) apud Edwards (2008) considera construção sustentável a criação e gestão de edifícios saudáveis, baseados em princípios ecológicos e no uso eficiente dos recursos.

O termo "saudáveis" aparece em comum nas definições acima caracterizando uma edificação onde a permanência do usuário é agradável, que com a devida manutenção é um espaço durável e que sua implantação não representa a destruição do meio, mas sim abrigo em harmonia com os ecossistemas, o que não descarta a tecnologia, mas utiliza-a com instrumento para alcançar a sustentabilidade.

A questão de gestão dos edifícios mencionadas por Edwards, já havia sido tratada por Yeang (1995) que ressalta a importância de estratégias de projeto que deem diretrizes de funcionamento.

En un planteamiento ecológico del proyecto, el proyectista necesita predecir y verificar toda la gama de interacciones y consecuencias del proyecto, no sólo antes de su construcción, sino durante su funcionamento o uso. (YEANG, 1995, p.14)

Em uma abordagem ecológica com o projeto, o designer precisa prever e verificar toda a gama de interações e consequências do projeto, não só antes da construção, mas, durante o seu funcionamento ou utilização (tradução livre).

O termo "Ecoedifício" foi utilizado por Adam (2011, p.9) para caracterizar o produto da arquitetura sustentável, um termo amplo que concilia os edifícios aos ecossistemas naturais. Segundo o autor este termo sintetiza "arquitetura bioclimática, geobiologia, ecotech, bioconstrução, tradições do Feng-Shui, do Sthapatya Veda, tecnologia dos materiais, a tecnologia de ponta, ecologia, alternativas energéticas e do conhecimento contemporâneo em: psicologia, física e biologia, neurociências, etc".

Assim, ecoedifício é um conceito dinâmico e progressivo de qualificação, que integra: indivíduo, edifício e ecossistemas, permitindo que todos assimilem-se harmonicamente. O objetivo é, desde o projeto, conhecer e atuar sobre os ciclos de recursos e energias nos edifícios, (em todas as fases de sua vida, construção, consumo, demolição, etc...), avaliando as consequências desta atuação (ADAM, 2011, p.9-10).

É possível analisar que os conceitos abordados acompanham a definição de sustentabilidade que integra o equilíbrio entre os aspectos econômico, social e ambiental, conceito conhecido como tripple bottom line. $\mathrm{O}$ aspecto ambiental é demonstrado de maneira clara e direta na relação com o ambiente e na análise do ciclo de vida do edifício, mas também se percebe a dimensão social e econômica. A social manifesta-se na preocupação com conforto e qualidade de vida dos usuários da edificação, e a econômica nas questões de durabilidade, manutenção, transporte de materiais investimento em tecnologias, e análise do custo de vida. 
Neste sentido, Salgado e colaboradores $(2012$, p.83) apresentam uma pesquisa realizada no Reino Unido pelo CIRIA (Construction Industry Research and Information Association). Tabela 1 apresenta Temas-chave para a construção sustentável.

Tabela 1: Temas-chave para a construção sustentável

\begin{tabular}{|c|c|}
\hline \multirow{2}{*}{ Temas ambientais } & Subtemas \\
& $\begin{array}{c}\text { Evitar poluição } \\
\text { Proteção e melhoria da biodiversidade } \\
\text { Melhoria de eficiência energética } \\
\text { Uso eficiente de recursos }\end{array}$ \\
\hline Temas sociais & $\begin{array}{c}\text { Respeito à equipe de funcionários } \\
\text { Relacionamento com comunidades locais } \\
\text { Estabelecimento de parcerias }\end{array}$ \\
\hline Temas econômicos & Aumento de produtividade e lucro \\
& Melhoria no projeto (produto oferecido) \\
& Monitoramento e relato de desempenho versus metas \\
\hline
\end{tabular}

Fonte: SALGADO et al. 2012.

A partir da análise do quadro 01 percebemos que alguns dos subtemas apesar de receberem uma determinada classificação são comuns a outros temas. Nos temas ambientais está a melhoria da eficiência energética. A eficiência energética das edificações é importante para otimizar os níveis de consumo e consequentemente reduzir o impacto ambiental de geração de energia. Apesar de ter sido classificada como um subtema ambiental, a eficiência energética influencia também os aspectos econômicos, pois tende à redução de custos com energia elétrica com um desempenho técnico satisfatório. O mesmo ocorre com o uso eficiente de recursos. Estes exemplos demonstram que os aspectos ambientais, sociais e econômicos estão interligados e interferem uns nos outros.

É necessário também afirmar as vantagens da arquitetura sustentável sobre a arquitetura tradicional. Apesar de a construção sustentável necessitar de maior investimento inicial, é consenso entre os autores que estes custos de construção são compensados com a redução de custos operacionais (BORGES \& MORAES, 2013). Este tipo de construção também colabora para a melhoria da imagem dos empreendedores perante a sociedade e tem sido explorada como marketing verde. A Tabela 2 apresenta benefícios do ambientalismo na indústria da construção.

Tabela 2: Benefícios do ambientalismo na indústria da construção

\begin{tabular}{|l|l|}
\hline 1 & Redução de custos \\
\hline 2 & Garantia do cumprimento da legislação \\
\hline 3 & Antecipação a legislação futura \\
\hline 4 & Redução de riscos ambientais \\
\hline 5 & Melhores relações com os legisladores \\
\hline 6 & Melhor imagem pública \\
\hline 7 & Aumento das oportunidades de mercado \\
\hline
\end{tabular}

Fonte: EDWARDS, 2008.

Edificações sustentáveis "podem produzir sua própria energia, captar e reciclar sua própria água, utilizar materiais reciclados e promover a reutilização dos resíduos, além de manter o equilíbrio entre $\mathrm{o}^{\mathrm{CO}_{2}}$ (dióxido de carbono) produzido durante sua construção e uso, e o $\mathrm{CO}_{2}$ 
transformado novamente em oxigênio, mediante o plantio de árvores em outras áreas. (EDWARDS, 2008, p.5)".

Em síntese, a construção sustentável é vantajosa pois se implanta de forma harmoniosa ao ambiente, suprindo a necessidade humana de abrigo com qualidade de vida e inclusive produzindo os recursos que retirou do ambiente durante sua construção, podendo contribuir para geração de recursos durante sua vida útil.

\title{
2.2 Eficiência energética na arquitetura
}

Dentre as características da edificação sustentável, a eficiência energética se apresenta como tema de grande relevância. É consenso entre os autores estudados que o ecoedifício necessita ser eficiente no uso dos recursos naturais, principalmente pela importância deste recurso na vida das pessoas e pelo impacto ambiental que a geração de energia elétrica ocasiona no meio ambiente, sendo urgentes as medidas de geração alternativa e uso.

Com o desenvolvimento da tecnologia da informação, da internet e dos equipamentos eletroeletrônicos, o homem utiliza cada vez mais energia. Ao mesmo tempo, enfrentamos problemas quanto a disponibilidade pelo uso majoritário de fontes de energia não renováveis, e também porque a maioria da energia elétrica utilizada nas edificações advém das hidrelétricas e a escassez de água tem atingido níveis alarmantes atualmente. A disponibilidade de água e energia é um dos grandes problemas da crise ambiental.

Braga aponta como possível solução desta crise a conservação da energia e seu o uso racional:

\begin{abstract}
Uma saída para a crise de energia é a conservação. Isso significa desenvolver meios de utilizar mais eficientemente as fontes hoje disponíveis. Os benefícios da conservação são enormes, prolongam o uso das fontes finitas e, principalmente, minimizam os impactos ambientais decorrentes da geração de energia. Paralelamente ao desenvolvimento de novas formas de aproveitamento energético, a conservação é um dos principais meios de gerenciar a crise atual. (BRAGA, 2005, p.56,57)
\end{abstract}

Nesse contexto, estima-se que os edifícios são responsáveis por grande parte da energia utilizada na maioria dos países. Segundo Yeang (1995) este consumo é entre $30 \%$ e $40 \%$, segundo Edwards (2008) o consumo dos edifícios é de $50 \%$ e um dado mais recente do Relatório Síntese do programa EEE - Eficiência Energética em Edifícios (BCSD, 2013) é que este consumo é de pelo menos $40 \%$. Portanto a eficiência energética de edifícios pode dar uma grande contribuição para a diminuição das alterações climáticas e utilização energética.

De acordo com Lamberts (1997, p.14), "a eficiência energética pode ser entendida como a obtenção de um serviço com baixo dispêndio de energia. Portanto, um edifício é mais eficiente energeticamente que outro quando proporciona as mesmas condições ambientais com menor consumo de energia".

A melhoria da eficiência energética de uma edificação pode ocorrer em usos finais específicos, como iluminação por exemplo, ou na edificação como um todo. A edificação eficiente deve buscar prover conforto ambiental ao usuário, evitar que os sistemas fiquem acionados 
quando não for necessário, minimizar a manutenção, reduzir o impacto ambiental e reduzir os custos relacionados a consumo de energia.

Buscando sistematizar e normatizar parâmetros para a eficiência energética nas edificações, foram desenvolvidos programas e métodos no Brasil e em outros países, dos quais apresenta-se os principais nos subitens a seguir.

\subsubsection{Programa Brasileiro de Etiquetagem e Procel Edifica}

O Programa Brasileiro de Etiquetagem - PBE é um projeto do Instituto Nacional de Metrologia, Normalização e Qualidade Industrial - INMETRO iniciado em 1984 para conservação e racionalização da energia no Brasil. A partir das discussões do PBE, o Brasil criou a Lei de Eficiência Energética - lei no 10.295 de 2001 que estabelece avaliação compulsória da eficiência energética para máquina e equipamentos consumidores de energia (INSTITUTO..., s/d).

O Programa Brasileiro de Etiquetagem - PBE é responsável por fornecer informações sobre o desempenho dos produtos quanto à eficiência energética. Os produtos são ensaiados em laboratórios e recebem etiquetas chamadas Etiqueta Nacional de Conservação de Energia - ENCE, que o classificam do nível "A" (mais eficiente) até "C" ou "G" (menos eficiente), a depender do produto, onde se entende que os mais eficientes utilizam melhor a energia, têm menor impacto ambiental e custam menos para funcionar. O objetivo desta etiquetagem é estimular a competitividade industrial a produzir equipamentos mais eficientes e proporcionar ao consumidor o conhecimento do consumo do equipamento para que este fator seja considerado nas compras (INSTITUTO..., s/d).

O Programa Nacional de Eficiência Energética em Edificações - Procel Edifica, foi criado em 2003 pela ELETROBRAS/PROCEL para promover o uso racional da energia elétrica em edificações, reduzindo os desperdícios e os impactos sobre o meio ambiente. O Procel Edifica também utiliza a ENCE para etiquetar edificações que são submetidas a avaliação de forma voluntária e podem ser classificadas do nível "A" (mais eficiente) até o nível "E" menos eficiente. A ENCE considera uma classificação geral para a edificação, dada a partir da avaliação e classificação de três sistemas para edificações comerciais, de serviços e públicas (iluminação, envoltória e condicionamento do ar) ou dois sistemas para edificações residenciais (envoltória e aquecimento de água). Esta avaliação é feita tanto na fase de projeto como também após a conclusão da obra (CENTRO BRASILEIRO...., $s / d)$.

A partir de junho de 2014, com a publicação da Instrução Normativa №02 do Ministério do Planejamento, Orçamento e Gestão, o Brasil tornou obrigatório que os novos edifícios públicos federais com mais de $500 \mathrm{~m}^{2}$ sejam construídos com nível "A" de eficiência energética (BRASIL, 2014). A metodologia de avaliação da conformidade está descrita no Regulamento Técnico da Qualidade para o Nível de Eficiência Energética em Edifícios Comerciais, de Serviços e Públicos (RTQ-C) e no Regulamento Técnico da Qualidade para o Nível de Eficiência Energética em Edificações Residenciais (RTQ-R) publicado pelo Programa Brasileiro de Edificações - PBE Edifica.

\subsubsection{Métodos e Certificações}

A seguir serão apresentados alguns métodos de auxílio ao projeto sustentável. São destacados o método inglês BREEAM - Building Research Establishment Environmental Assessment 
Method, o método francês HQE, e o norte-americano LEED, os quais são também sistemas de certificação da qualidade ambiental.

O BREEAM é um método criado no Reino Unido, mas com uma metodologia adaptável a todo o mundo pois alia-se a legislação local. O BREEAM avalia os seguintes critérios com diferentes pesos:
a) Gerenciamento - $12 \%$
b) Saúde e bem estar - $15 \%$
c) Energia - $19 \%$
d) Transporte - 8\%
e) Água - 6\%
f) Materiais $-12,5 \%$
g) Resíduos - 7,5\%
h) Uso da terra e ecologia - $10 \%$
i) Poluição - $10 \%$

A classificação baseia-se na pontuação acumulada e pode-se alcançar os conceitos: Pass (Aprovado) / Good (Bom) / Very Good (Muito Bom) / Excellent (Excelente) / Outstanding (Excepcional).

O método francês foi criado em 1996 pela Associação HQE - Haute Qualité Environmentale (Alta Qualidade Ambiental) por meio de um relatório contendo recomendações ou alvos ambientais em quatro categorias a serem atendidos pelo arquiteto ou engenheiro, no desenvolvimento dos projetos das edificações. As quatro categorias são:

(a) ecocontrução;

(b) ecogestão: incluindo a gestão da energia, da água, dos rejeitos da obra, assistência técnica e manutenção;

(c) conforto (térmico, acústico, visual); e

(d) saúde (qualidade do ar e da água) (SALGADO et al. 2012, p.82).

Cada categoria se desdobra em alvos com várias exigências e recomendações. Estas recomendações se aplicam de forma diferenciada conforme o tipo de projeto, terreno e peculiaridades de cada edificação, não existindo, portanto, uma única solução ideal. A metodologia HQE tem sido considerada na França como uma exigência nas concorrências públicas (SALGADO, CHATELET, FERNADEZ, 2012, p.83,89).

O método LEED (Leadership in Energy and Environmental Design), criado nos Estados Unidos, é um sistema internacional de certificação e orientação ambiental, atualmente utilizado em 143 países. O objetivo é incentivar a transformação dos projetos, obra e operação das edificações, sempre com foco na sustentabilidade de suas atuações (CGB BRASIL, s/d).

No LEED são avaliadas 7 dimensões das edificações. Todas elas possuem pré-requisitos (práticas obrigatórias) e créditos, recomendações que quando atendidas garantem pontos a edificação. A pontuação alcançada classifica a edificação em certificada, prata, ouro ou platina. As dimensões avaliadas pelo LEED são: Espaço sustentável; Eficiência do uso da água; Energia e atmosfera; Materiais e recursos; Qualidade ambiental interna; Inovação e processos; e créditos de prioridade regional (CGB BRASIL, $s / d$ ). 
Salgado e colaboradores (2012) afirmam que os métodos BREEAM e LEED baseiam-se na atribuição de créditos conforme o desempenho alcançado pela proposta. No método inglês, a equipe de projeto é livre para escolher quais critérios vão atender para alcançar a pontuação necessária à certificação; enquanto o método norte-americano possui pré-requisitos que devem ser todos atendidos além de uma pontuação mínima em cada requisito. O método LEED foi o primeiro a ser aplicado no Brasil, em 2007. A metodologia HQE foi adaptada ao Brasil resultando na certificação Aqua, em 2009.

Existem também métodos brasileiros, entre os quais se destaca o Selo Azul da Caixa Econômica Federal, criado em 2010. O selo é aplicado aos projetos habitacionais que são financiados pela Caixa para verificação da viabilidade do empreendimento. As edificações são avaliadas em 6 categorias, que incluem caráter social como investimento em educação e gestão de resíduos sólidos. Este selo supera os estrangeiros no aspecto social, os quais não se verificam nos demais métodos revelando, portanto, que o Brasil avança ao tratar a sustentabilidade também sob o aspecto social (SALGADO et al., 2012).

Em todos os métodos apresentados os critérios de avaliação podem ser divididos em técnicos e organizacionais, ambos fundamentais para a construção sustentável. No que se refere ao "produto-edificação" em todo o seu ciclo de vida, da concepção até a demolição, aplicam-se os critérios técnicos, e com relação às práticas cotidianas e operacionais que precisam ser definidas no projeto integrado aplicam-se os critérios organizacionais. Entende-se que os métodos apresentados contribuem para orientar empreendedores, arquitetos, engenheiros e construtores sobre os aspectos que devem ser analisados para que a edificação seja sustentável (SALGADO et al., 2012).

\subsection{Simulação computacional da eficiência energética na arquitetura}

O avanço da tecnologia da informação, com o desenvolvimento de softwares específicos para diversas áreas, influenciou no processo de projeto das edificações. Atualmente dispomos de diversos instrumentos de modelagem e simulação gráfica que podem auxiliar a concepção do projeto arquitetônico, avaliando as diversas soluções para que a proposta final obtenha os níveis de eficiência e qualidade ambiental requerido pelos diversos métodos.

Com relação à simulação da eficiência energética, Didoné e Pereira (2010, p.139) afirmam que "a avaliação do desempenho energético de edificações é uma tarefa complexa que envolve grande quantidade de variáveis interdependentes e conceitos multidisciplinares", por isto o uso de simulações computacionais permite realizar a análise de diversos cenários ainda na fase de projeto, ou mesmo após a construção, que seriam demasiadamente demorados e desgastantes, viabilizando a melhoria da qualidade dos projetos.

Este mesmo pensamento já havia sido defendido por Mendes et al (2005, p.48): "com a simulação computacional, pode-se estimar o consumo de energia, o custo desse consumo e até mesmo o impacto ambiental provocado pela alternativa de projeto antes mesmo de sua execução".

Existem softwares específicos para a simulação do desempenho térmico e energético, que analisam as edificações de forma geral e também por sistemas como, geometria do projeto arquitetônico, componentes e materiais construtivos, sistemas de iluminação e sistemas de condicionamento de ar (MENDES et al, 2005). 
No portal oficial do PROCEL (CENTRO..., s/d), existe uma lista com indicação de 41 simuladores úteis para projetos de eficiência energética com os respectivos links para downloads. Em geral, estes softwares possuem bases de dados onde é possível carregar dados climáticos horários de diversas localidades, o que permite que sejam representadas as situações de exposição da edificação à fatores como temperatura do ar, umidade relativa, radiação solar e ventos. Dentre os softwares específicos de eficiência energética destacamos:

a) Design Builder - é um software para modelagem de edifícios e simulações de desempenho ambiental, desde as fases iniciais de desenvolvimento do projeto. É integrado à ferramenta Energy Plus, desenvolvida pelo Departamento de Energia dos Estados Unidos, e permite analisar sistemas de aquecimento e resfriamento, iluminação, e ventilação, de forma a quantificar o seu consumo de energia. Com interface simples, ele fornece informações detalhadas, imagens e animações do projeto, além do acesso aos resultados com facilidade. (CENTRO..., s/d)

b) Ecotec - O Ecotect surgiu como uma demonstração de ideias contidas na tese do Dr. Andrew Marsh na Faculdade de Arquitetura e Belas Artes da Universidade da Austrália Ocidental. O primeiro lançamento comercial ocorreu em 1996, e em 2009 o software foi adquirido pela Autodesk. Faz simulações de sombras e reflexos, análise solar, iluminação, térmica, acústica e ventilação.

c) SE3 - O LABEEE, Laboratório de Eficiência Energética em Edificações, localizado na UFSC, disponibiliza para uso, de forma livre para fins educativos. O S3E é uma ferramenta disponível como um site na web, que realiza simulação de eficiência energética utilizando como simulador o Energy Plus. O Simulador S3E é uma ferramenta que permite avaliar o nível de eficiência energética de edificações comerciais segundo o Programa Brasileiro de Etiquetagem (RTQ-C) (S3E, s/d).

Apesar de existirem diversas opções de simuladores de eficiência energética, Freire e Amorim (2011) afirmam que "a maior parte dessas ferramentas está distante do cotidiano de escritórios de arquitetura, ficando seu uso ainda restrito aos especialistas do setor" pois existe uma "resistência por parte dos projetistas em utilizar ferramentas de avaliação, principalmente aquelas que tratam das variáveis apenas por valores numéricos". Da mesma forma Mendes et al (2005) já concordava que a simulação está afastada do cotidiano dos escritórios: "o uso de simulação de edificações no Brasil ainda está concentrado nas instituições de ensino e pesquisa". Segundo os autores é necessária "a elaboração de interfaces simplificadas, que reduzam o tempo gasto na modelagem e análise de diferentes alternativas ainda na etapa de anteprojeto, na qual são assumidos os conceitos principais, que poderão sofrer poucas alterações no decorrer do projeto" (MENDES et al, 2005, p.59).

\section{METODOLOGIA}

A elaboração deste artigo surgiu a partir de uma pesquisa teórica com base em revisão bibliográfica sobre três temáticas selecionadas: arquitetura sustentável, bioclimática e ecoarquitetura, eficiência energética nas edificações e simulação computacional para projetos de eficiência energética.

Para esse estudo foram adotados os seguintes procedimentos: levantamento inicial de material para leitura, através de pesquisas em livros para obter textos norteadores, buscas nos periódicos da Capes e revistas científicas atualizadas. Foi feita a triagem e seleção do material para 
leitura relacionada ao objetivo. As leituras foram registradas em fichamentos individuais de cada referência e construção do texto através do agrupamento de ideias semelhantes ou opostas dos diversos autores, apresentando uma reflexão sobre cada temática.

\section{RESULTADOS E DISCUSSÕES}

No âmbito conceitual, percebe-se que a arquitetura sustentável é bem definida e que existe uma concordância entre os autores com relação às definições e características do projeto sustentável. Entretanto, verificou-se que não existe uma padronização dos termos utilizados, sendo que o ecoedifício, a edificação sustentável e a construção ecológica possuem basicamente o mesmo significado. Em síntese um projeto sustentável envolve a economia energética, a análise do ciclo de vida, a promoção de espaços saudáveis e confortáveis que atendam às necessidades sociais e economicamente viáveis.

Verifica-se que a arquitetura sustentável é complexa por precisar solucionar diversos aspectos interligados. Entretanto, o desafio de projetar em sintonia com o meio ambiente é possível e válido. Segundo Edwards (2008), "se a sociedade aceitar a ideia de projetos de edificações sustentáveis, o desenvolvimento sustentável das cidades será uma consequência", por isso é necessário conscientizar os profissionais de arquitetura e construção do seu papel de disseminador da sustentabilidade.

A eficiência energética das edificações é essencial para alcançar a sustentabilidade nas mesmas, e para tal têm sido explorados diversos métodos e instrumentos. Com relação aos métodos de avaliação e certificação citados, Reed et al (2009) apud Salgado e colaboradores (2012) fez uma comparação entre os principais métodos internacionais de auxílio ao projeto com qualidade ambiental. A Tabela 3, apresenta a Comparação entre BREEAM, LEED e HQE.

Tabela 3: Comparação entre BREEAM, LEED e HQE

\begin{tabular}{|l|c|c|c|}
\hline Critério & BREEAM & LEED & HQE \\
\hline Energia & $\mathrm{X}$ & $\mathrm{X}$ & $\mathrm{X}$ \\
\hline Emissão de $\mathrm{CO}_{2}$ & $\mathrm{X}$ & & $\mathrm{X}$ \\
\hline Ecologia & $\mathrm{X}$ & $\mathrm{X}$ & $\mathrm{X}$ \\
\hline Economia & & & $?$ \\
\hline Saúde e bem-estar & $\mathrm{X}$ & & $\mathrm{X}$ \\
\hline Qualidade do ar interno & $\mathrm{X}$ & $\mathrm{X}$ & $\mathrm{X}$ \\
\hline Inovação & $\mathrm{X}$ & $\mathrm{X}$ & $?$ \\
\hline Implantação no terreno & $\mathrm{X}$ & $\mathrm{X}$ & $\mathrm{X}$ \\
\hline Gerenciamento & $\mathrm{X}$ & & $?$ \\
\hline Materiais & $\mathrm{X}$ & & $?$ \\
\hline Poluição & $\mathrm{X}$ & $\mathrm{X}$ & $\mathrm{X}$ \\
\hline Tecnologias renováveis & $\mathrm{X}$ & $\mathrm{X}$ & $?$ \\
\hline Transporte & $\mathrm{X}$ & $\mathrm{X}$ & $?$ \\
\hline Desperdício & $\mathrm{X}$ & & $\mathrm{X}$ \\
\hline Água & $\mathrm{X}$ & $\mathrm{X}$ & $\mathrm{X}$ \\
\hline
\end{tabular}

Fonte: SALGADO et al., 2012.

A partir da Tabela 3 foi possível observar que temas relevantes como energia, água, poluição e qualidade do ar interno estão presentes em todas as metodologias, enquanto os demais aspectos variam. O método BREEAM é o que avalia a maioria dos temas, mas existem muitas interrogações no método $\mathrm{HQE}$, como se o autor tivesse dúvidas sobre a abordagem em 
determinados assuntos, é possível que o método trate da temática de forma indireta que não acumule pontuação. Salgado e colaboradores (2012), consideram que, infelizmente, esses três métodos estrangeiros de projeto e certificação não oferecem possibilidade de comparação, pois possuem abordagens diferentes.

Quanto ao uso de simulações gráficas, percebe-se que a maioria dos softwares disponíveis são pagos, o que exige um investimento por parte dos projetistas para utilizá-los. E mesmo existindo opções gratuitas, tem-se a cultura de que ferramentas como estas são utilizadas apenas por especialistas desta área, o que muitas vezes afasta os simuladores do cotidiano dos escritórios. Como a compulsoriedade da eficiência energética das edificações iniciou apenas no segundo semestre de 2014 e unicamente para novas edificações públicas federais, ainda não há um reflexo na prática projetual de arquitetura. A tendência é que a preocupação em conceber edificações mais eficientes cresça, não apenas no setor público, mas também nos empreendimentos privados.

\section{CONCLUSÃO}

Independente do termo utilizado ser arquitetura sustentável, bioarquitetura ou arquitetura bioclimática, existem profissionais e pesquisadores dedicados à estudos onde as construções gerem menor impacto de implantação e operação e maior eficiência no uso de recursos naturais, acompanhando as atuais reflexões sobre sustentabilidade. Estes conceitos precisam ser repensados diariamente na produção arquitetônica para alcançarmos a construção de cidades sustentáveis pois a preservação dos recursos naturais existentes é urgente para garantir a satisfação das necessidades da nossa sociedade.

Quanto à eficiência energética, os métodos abordados podem ser utilizados como parâmetros projetuais, ainda que não sejam adotadas as certificações, pois trazem referências de bons desempenhos em diferentes áreas. Considerando o cenário atual onde existe a obrigatoriedade de comprovação de desempenho técnico para as edificações federais, e a tendência futura de extensão desta exigência para as esferas e setores, faz-se necessário o conhecimento e adoção destes parâmetros pelos arquitetos e urbanistas, bem como os demais envolvidos na construção civil.

É preciso explorar os instrumentos de simulação computacional para promover a maior utilização dos recursos com menor consumo de energia, desde a concepção do projeto e avaliar após a construção e operação do edifício para criar sistemas de retroalimentação e buscar a melhoria contínua do processo de projeto.

\section{REFERÊNCIAS BIBLIOGRÁFICAS}

1. ADAM, Roberto Sabatella. Princípios do ecoedifício: interação entre ecologia, consciência e edifício. São Paulo: Aquariana, 2001.

2. BORGES, Aline Vieira; MORAES, Anselmo Fábio de 2013. Edifícios públicos: caminhos para a concepção de projetos sustentáveis. 60 PROJETAR: Salvador, 2013. Disponível em: <http://projedata.grupoprojetar.ufrn.br/dspace/handle/123456789/1837> Acesso em: 23 set 2014 , às 15:46.

3. BRASIL. MINISTÉRIO DO PLANEJAMENTO, ORÇAMENTO E GESTÃO. Instrução Normativa 
№02/2014. Disponível em: <http://www.comprasgovernamentais.gov.br/paginas/instrucoes -normativas/instrucao-normativa-no-2-de-4-de-junho-de-2014>. Acesso em: 10 fev. 2015.

4. CENTRO BRASILEIRO DE INFORMAÇÃO DE EFICIENCIA ENERGETICA. Disponível em: $<$ http://www.procelinfo.com.br/main.asp?View $=\{8$ E03DCDE-FAE6-470C-90CB922E4DD0542C\}>. Acesso em: 18 fev. 2015.

5. CGB BRASIL. Green Building Council Brasil. Certificação LEED. Disponível em:<http://www .gbcbrasil.org.br/sobre-certificado.php> Acesso em: 10 fev. 2015.

6. CORBELLA, Oscar; YANNAS, Simos. Em busca de uma arquitetura sustentável para os trópicos - conforto ambiental. Rio de Janeiro: Revan, 2003.

7. DIDONÉ, Evelise Leite; PEREIRA, Fernando Oscar Ruttkay. Simulação computacional integrada para a consideração da luz natural na avaliação do desempenho energético de edificações. Ambiente Construído, Porto Alegre, v. 10, n. 4, p. 139-154, out./dez. 2010. Disponível em: <htt p://www.seer.ufrgs.br/ambienteconstruido/article/view/12108>. Acesso em: $01 \mathrm{dez} .2014$.

8. EDWARDS, Brian. O guia básico para a sustentabilidade. Barcelona: Editorial Gustavo Gili, 2008.

9. FREIRE, Márcia Rebouças; AMORIM, Arivaldo Leão de. A abordagem BIM como contribuição para a eficiência energética no ambiente construído. V TIC - Salvador, Bahia,Brasil, 4 e 5 de agosto de 2011.

10. GONÇALVES, Joana Carla Soares; DUARTE, Denise Helena Silva. Arquitetura sustentável: uma integração entre ambiente, projeto e tecnologia em experiências de pesquisa, prática e ensino. Ambiente Construído, Porto Alegre, v. 6, n. 4, p. 51-81, out./dez. 2006. Disponível em: <http://www.seer.ufrgs.br/index.php/ambienteconstruido/article/view/3720/2071>. Acesso em: 09 jan. 2015.

11. HICKEL, Denis Kern. A (in)sustentabilidade na arquitetura. Arquitextos, São Paulo, ano 06, n. 064.06, Vitruvius, set. 2005. Disponível em: <http://www.vitruvius.com.br/revistas/read/ arquitextos/06.064/426>. Acesso em: 09 jan. 2015.

12. INSTITUTO NACIONAL DE METROLOGIA, NORMALIZAÇÃO E QUALIDADE INDUSTRIAL. Disponível em: <http://www2.inmetro.gov.br/pbe/conheca_o_programa.php>. Acesso em: 18 fev. 2015.

13. MENDES, Nathan; WESTPHAL, Fernando Simon; LAMBERTS, Roberto; CUNHA NETO, José A. Bellini da. Uso de instrumentos computacionais para análise do desempenho térmico e energético de edificações no Brasil. Ambiente Construído, Porto Alegre, v. 5, n. 4, p. 47-68, out./dez. 2005. Disponível em: <http://www.seer.ufrgs.br/ambienteconstruido/article/down load/3657/2013>. Acesso em: 01 dez. 2014.

14. S3E. Simulador Eficiência Energética em Edificações. Disponível em:<http://www.s3e. ufsc.br/> Acesso em: 10 fev. 2015.

15. SALGAdO, Mônica Santos; CHATELET, Alain; FERNANDEZ, Pierre. Produção de edifícios sustentáveis: desafios e alternativas. Ambiente Construído, Porto Alegre, v. 12, n. 4, p. 81-99, out./dez. 2012. Disponível em: <http://seer.ufrgs.br/ambienteconstruido/article/view/22 603>. Acesso em: 09 jan. 2015.

16. YEANG, Ken. Proyectar con la naturaleza: bases ecológicas para el proyecto arquitectónico. Barcelona: Editoral Gustavo Gili, 1995. 